\title{
Desenvolvimento folicular em ovários de fetos zebuínos (Bos taurus indicus)
}

\author{
Cristina Maria Rodrigues Monteiro* \\ Michael Babosa Biagi \\ Silvia Helena Venturoli Perri \\ Roberto Gameiro de Carvalho \\ Guilherme de Paula Nogueira

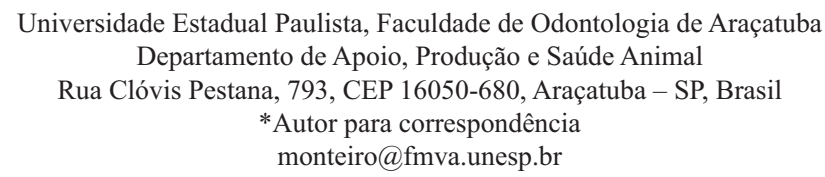

Submetido em 16/10/2008

Aceito para publicação em 06/04/2009

\section{Resumo}

Neste trabalho foram utilizadas 36 amostras de ovários de fetos fêmeas (com três a oito meses de gestação) da raça Nelore (Bos taurus indicus) separados em seis grupos com seis amostras cada. Para as análises histológicas e morfométricas, os ovários foram processados em resina paraplast e submetidos à coloração com Hematoxilina e Eosina. Foram analisadas as estruturas histológicas presentes nos diferentes estágios fetais e efetuadas mensurações dos diâmetros máximo e mínimo, perímetro e área dos folículos primordiais, primários e pré-antrais. Concluiu-se que: 1 - nos fetos a partir de três meses de gestação, os ovários apresentaram folículos primordiais, 2 - a partir dos quatro meses de gestação, os ovários já continham folículos primários, 3 - os folículos pré-antrais e antrais surgiram nos ovários de fetos a partir de seis meses de gestação, 4 - as maiores médias foram obtidas aos sete meses de gestação para folículos primordiais e pré-antrais, tornando a decair aos oito meses.

Unitermos: bovinos, fetos, histologia, morfometria, ovários

\section{Abstract}

Follicular development in ovaries of zebu fetuses (Bos taurus indicus). In this study we utilized 36 samples from the ovaries of female fetuses (with three to eight months' gestation) of the Nelore breed of zebus (Bos taurus indicus) in six separate groups with six samples each. For the histological and morphometric analysis, the ovaries were processed with paraplast and stained with Hematoxylin and Eosin. We analyzed the histological structures in different fetal stages, and measurements were taken of the maximum and minimum diameter, perimeter and area of primordial, primary and pre-antral follicles. It was concluded that: 1 - in fetuses with three months of pregnancy, the ovaries had primary follicles, 2 - from four months of pregnancy, the ovaries already contained primary follicles, 3 - the pre-antral and antral follicles emerged in ovaries of fetuses from six months of pregnancy, 4 - the highest averages for primordial and pre-antral follicles were obtained at seven months of pregnancy, returning to decline at eight months.

Key words: bovine, fetuses, histology, morphometry, ovaries 


\section{Introdução}

As variações morfológicas que as estruturas dos órgãos reprodutores sofrem nos diferentes estágios fetais, merecem um estudo mais detalhado, sobretudo para se compreender melhor os mecanismos que controlam o seu desenvolvimento, já que os estudos morfológicos do aparelho reprodutor feminino são, em grande parte, realizados em bovinos adultos ou em crescimento (Diniz et al., 2005).

Os raros estudos em fetos são feitos em raças européias (Diniz et al., 2005), portanto, neste trabalho, objetivou-se contribuir com dados quantitativos, sobre o desenvolvimento pré-natal de ovários de fetos zebuínos para tentar verificar o período de surgimento dos folículos ovarianos e seus estágios de crescimento.

Diniz et al. (2005) relataram em fetos da raça Nelore que os folículos primordiais, em crescimento e antrais surgem aproximadamente, aos 95, 140 e 180 dias de gestação e Mbassa (1989) por sua vez, afirmou que em fetos zebuínos, os folículos primordiais são formados a partir de 60 dias pós-coito e pouco antes dos quatro meses os folículos primários já estavam presentes no córtex ovariano. Estes fatos revelam a antecipação do surgimento da foliculogênese em fetos zebus em relação às raças européias.

Em várias espécies de mamíferos, os oócitos e folículos primordiais, apresentam número reduzido, principalmente a partir da segunda metade da gestação (Motta e Makabe, 1986). Folículos em crescimento (pré-antrais e antrais) também sofrem perda contínua no final da gestação ou mesmo logo após o nascimento (Mc Natty et al., 1987; Hopper et al., 1993; Erickson, 1966) que seriam conseqüência dos mecanismos de atresia folicular (Mclaren, 2000).

Isto posto, justifica-se a difusão do uso de análises morfométricas, como métodos quantitativos de grande valia, para se estudar o desenvolvimento morfológico de várias estruturas e mesmo de órgãos em formação.

\section{Material e Métodos}

Para esta pesquisa foram utilizadas 36 amostras de ovários de fetos fêmeas da raça Nelore (Bos taurus indicus) coletados no frigorífico de Araçatuba, separados em 6 grupos com seis amostras cada um: $1^{\circ}$ grupo - fetos com aproximadamente três meses de gestação, $2^{\circ}$ grupo fetos com quatro meses de gestação, $3^{\circ}$ grupo - fetos com cinco meses de gestação, $4^{\circ}$ grupo - fetos com seis meses de gestação, $5^{\circ}$ grupo - fetos com sete meses de gestação e $6^{\circ}$ grupo - fetos com oito meses de gestação. As idades dos fetos foram avaliadas conforme a tabela de CrownRump (Richardson et al., 1990). Com a finalidade de se realizar as análises histológica e morfométrica, foram coletados os ovários inteiros que foram fixados em solução tamponada a $5 \%$ de paraformaldeido por $24 \mathrm{~h}$, após o qual foi retirado apenas um fragmento em corte longitudinal de aproximadamente $3 \mathrm{~mm}$ de espessura para processamento em técnica histológica com resina paraplast. Os cortes histológicos de aproximadamente $5 \mu \mathrm{m}$ de espessura foram posteriormente submetidos à coloração com Hematoxilina e Eosina para serem examinados ao microscópio de luz Olympus CBA. Foram analisadas as estruturas histológicas pertinentes a cada período de gestação. Para a histomorfometria foram efetuadas mensurações dos folículos primordiais, primários (ou unilaminares) e pré-antrais (ou multilaminares) sendo elas, diâmetros máximo e mínimo, perímetro e área (10 amostras para cada tipo folicular, quando existentes). Para esse fim utilizou-se um programa de análises de imagens para histomorfometria, o Image $\mathrm{J}$ e os dados obtidos, submetidos à análise de variância e as médias comparadas por meio do teste de Tukey, consideradas significativas quando $\mathrm{P}<0,05$. As análises estatísticas foram efetuadas com o programa computacional SAS (Statistical Analysis System) versão 8.2.

\section{Resultados}

\section{Histológicos}

Nos diferentes períodos de gestação os ovários estavam revestidos por epitélio simples cúbico, às vezes com áreas de epitélio simples pavimentoso e logo abaixo túnica albugínea de tecido conjuntivo denso. Os 
fetos com três meses de gestação apresentaram córtex ovariano com grande quantidade de folículos primordiais localizados profundamente próximos a medula e alguns folículos transicionais (oócitos envolvidos por células pavimentosas e cúbicas). Aproximadamente aos quatro meses de gestação, surgiram folículos primários localizados profundamente (Figura 1a) e alguns mais superficialmente no córtex ovariano.

No período fetal correspondente a cinco meses de gestação, os folículos primordiais e primários estavam localizados logo abaixo da cápsula epitelial que reveste o órgão externamente. A região medular, nesses períodos de gestação, manteve o mesmo padrão histológico encontrado nos fetos com três a quatro meses, mal delimitada do córtex, formada por tecido conjuntivo denso e fibras colágenas dispostas em arranjos concêntricos e presença discreta de vasos sanguíneos de pequeno calibre.
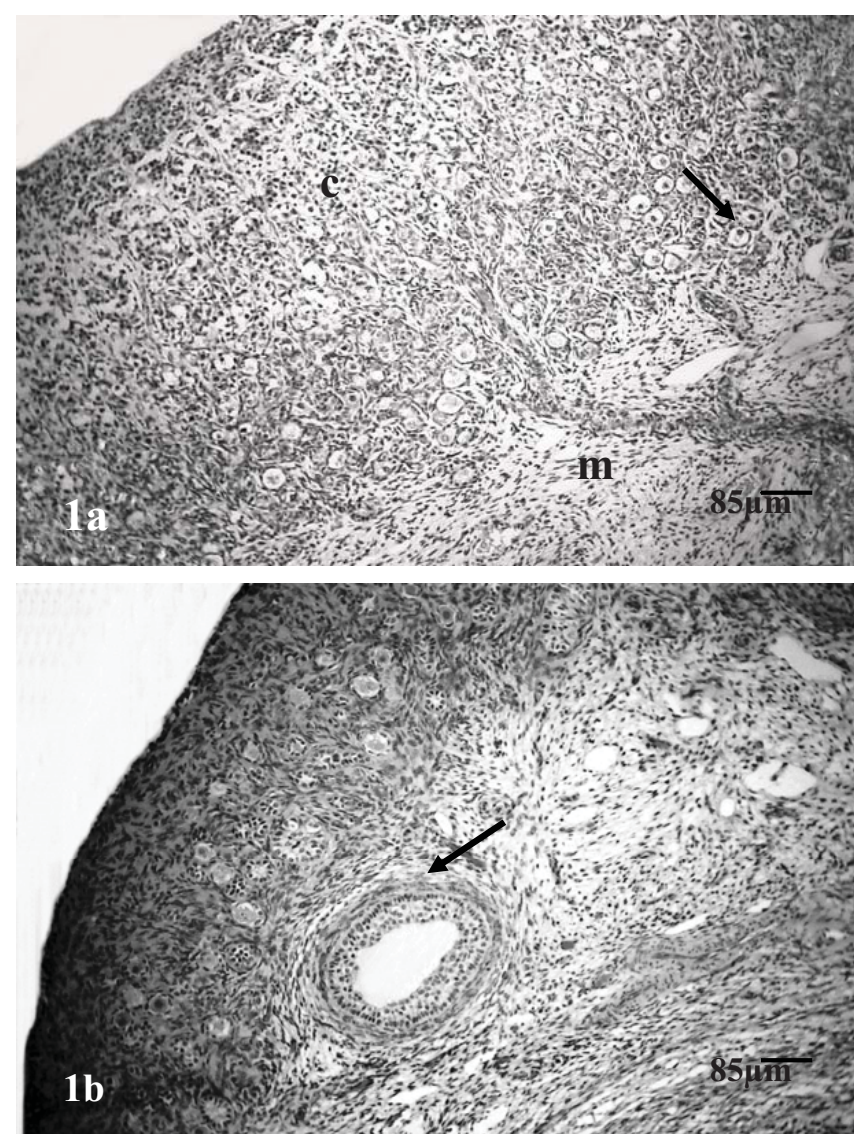

FIGURA 1: Fotomicrografia de ovário. 1a - Feto com quatro meses de gestação. Córtex (c). Folículos primários (seta). Medula (m). Hematoxilina e Eosina. 40X. 1b - Feto com seis meses de gestação. Folículo antral (seta). Hematoxilina e Eosina. 40X.
A partir dos seis meses de gestação, surgiram no córtex ovariano, folículos pré-antrais, antrais e atrésicos cujas características principais são desprendimento das células da granulosa da membrana basal e morte do oócito. Os folículos pré-antrais estavam localizados na parte intermediária e superficial do córtex ovariano e no $6^{\circ}$ mês já se pode constatar oócitos rodeados por zona pelúcida (Figura 1b). A região medular estava bem delimitada da cortical, formada por tecido conjuntivo denso com áreas de tecido conjuntivo frouxo e pequenos vasos sanguíneos.

\section{Morfométricos}

Com observação nas Tabelas 1, 2 e 3, constatou-se que não houve diferença estatisticamente significante entre as medidas dos folículos, comparando-se os diâmetros dos folículos primordiais, primários e préantrais respectivamente com exceção para o feto de sete meses de gestação. Neste período as médias foram mais elevadas para os folículos primordiais, ocorrendo decréscimo das mesmas para os fetos no $8^{\circ}$ mês, voltando aos parâmetros correspondentes aos fetos de três a seis meses de gestação (Tabela 1).

As mensurações dos folículos pré-antrais atingiram o ápice no período gestacional de sete meses e apresentaram queda nos fetos com oito meses de gestação. As medidas para este período (oito meses) foram menores que as medidas relativas aos fetos com seis meses de gestação (Tabela 3).

A Tabela 4 e a Figura 2 mostram os valores dos diferentes tipos de folículos ovarianos, comparando-se fetos nos períodos de seis a oito meses de gestação. Verificou-se que não houve diferença significante entre as mensurações dos folículos primordiais e primários, porém houve diferença significante entre estes e os folículos pré-antrais.

Os folículos primários mantiveram medidas com pequenas variações sem diferença significativa em todos os períodos gestacionais (Tabela 2). 
TABELA 1: Médias e desvio padrão dos diâmetros máximo e mínimo, área e perímetro dos folículos primordiais de fetos zebuínos nos vários períodos de gestação. Araçatuba (SP), 2008.

\begin{tabular}{ccccc}
\hline \multirow{2}{*}{$\begin{array}{c}\text { Idade } \\
(\text { meses })\end{array}$} & \multicolumn{2}{c}{ Diâmetro $(\boldsymbol{\mu m})$} & Área $\left(\boldsymbol{\mu m}^{2}\right)$ & \multirow{2}{*}{ Perímetro $(\boldsymbol{\mu m})$} \\
\cline { 2 - 4 } & $33,59 \pm 4,23 \mathrm{~b}$ & $25,94 \pm 3,32 \mathrm{~b}$ & $765,72 \pm 217,81 \mathrm{~b}$ & $99,69 \pm 13,48 \mathrm{~b}$ \\
4 & $34,77 \pm 2,04 \mathrm{~b}$ & $27,37 \pm 1,08 \mathrm{~b}$ & $757,45 \pm 26,18 \mathrm{~b}$ & $101,73 \pm 5,07 \mathrm{~b}$ \\
5 & $34,40 \pm 6,39 \mathrm{~b}$ & $28,66 \pm 6,15 \mathrm{~b}$ & $823,07 \pm 282,81 \mathrm{~b}$ & $104,85 \pm 18,52 \mathrm{~b}$ \\
6 & $33,90 \pm 3,11 \mathrm{~b}$ & $27,97 \pm 3,01 \mathrm{~b}$ & $763,35 \pm 151,66 \mathrm{~b}$ & $99,91 \pm 8,53 \mathrm{~b}$ \\
7 & $44,97 \pm 2,53 \mathrm{a}$ & $35,86 \pm 2,65 \mathrm{a}$ & $1388,90 \pm 168,91 \mathrm{a}$ & $134,80 \pm 7,08 \mathrm{a}$ \\
8 & $34,04 \pm 3,43 \mathrm{~b}$ & $26,51 \pm 3,56 \mathrm{~b}$ & $760,57 \pm 222,03 \mathrm{~b}$ & $100,42 \pm 14,25 \mathrm{~b}$ \\
\hline
\end{tabular}

Médias com letras distintas na mesma coluna diferem entre si pelo teste de Tukey $(\mathrm{P}<0,05)$.

TABELA 2: Médias e desvio padrão dos diâmetros máximo e mínimo, área e perímetro dos folículos primários de fetos zebuínos nos vários períodos de gestação. Araçatuba (SP), 2008.

\begin{tabular}{ccccc}
\hline \multirow{2}{*}{$\begin{array}{c}\text { Idade }(\mathbf{m e}- \\
\text { ses) }\end{array}$} & \multicolumn{2}{c}{ Diâmetro $(\boldsymbol{\mu m})$} & Área $\left(\boldsymbol{\mu m ^ { 2 } )}\right.$ & \multirow{2}{*}{ Perímetro $(\boldsymbol{\mu m})$} \\
\cline { 2 - 4 } & Máximo & Mínimo & $1077,10 \pm 186,53 \mathrm{a}$ & $119,81 \pm 9,75 \mathrm{a}$ \\
5 & $40,32 \pm 4,10 \mathrm{a}$ & $31,26 \pm 3,77 \mathrm{a}$ & $1177,16 \pm 201,21 \mathrm{a}$ & $123,93 \pm 10,53 \mathrm{a}$ \\
6 & $41,95 \pm 4,19 \mathrm{a}$ & $34,30 \pm 3,81 \mathrm{a}$ & $1144,06 \pm 168,47 \mathrm{a}$ & $122,53 \pm 9,37 \mathrm{a}$ \\
7 & $42,66 \pm 1,77 \mathrm{a}$ & $34,13 \pm 2,71 \mathrm{a}$ & $1364,45 \pm 122,78 \mathrm{a}$ & $133,84 \pm 5,39 \mathrm{a}$ \\
8 & $44,71 \pm 2,19 \mathrm{a}$ & $35,62 \pm 2,28 \mathrm{a}$ & & $135,75 \pm 23,39 \mathrm{a}$ \\
\hline
\end{tabular}

Médias com letras distintas na mesma coluna diferem entre si pelo teste de Tukey $(\mathrm{P}<0,05)$.

TABELA 3: Médias e desvio padrão dos diâmetros máximo e mínimo, área e perímetro dos folículos pré-antrais de fetos zebuínos nos vários períodos 6, 7 e 8 meses de gestação. Araçatuba (SP), 2008.

\begin{tabular}{|c|c|c|c|c|}
\hline \multirow{2}{*}{$\begin{array}{c}\text { Idade (me- } \\
\text { ses)) }\end{array}$} & \multicolumn{2}{|c|}{ Diâmetro $(\mu \mathrm{m})$} & \multirow{2}{*}{ Área $\left(\mu \mathrm{m}^{2}\right)$} & \multirow{2}{*}{ Perímetro $(\mu \mathrm{m})$} \\
\hline & Máximo & Mínimo & & \\
\hline 6 & $76,52 \pm 17,03 \mathrm{a}$ & $58,77 \pm 12,68 \mathrm{ab}$ & $3912,30 \pm 1789,54 \mathrm{a}$ & $223,29 \pm 50,90 \mathrm{a}$ \\
\hline 7 & $84,01 \pm 13,97 \mathrm{a}$ & $68,05 \pm 9,78 \mathrm{a}$ & $5106,05 \pm 1502,37 \mathrm{a}$ & $255,43 \pm 39,64 \mathrm{a}$ \\
\hline 8 & $65,75 \pm 13,93 \mathrm{a}$ & $49,23 \pm 7,51 \mathrm{~b}$ & $2900,62 \pm 966,20 \mathrm{a}$ & $195,28 \pm 29,93 \mathrm{a}$ \\
\hline
\end{tabular}

Médias com letras distintas na mesma coluna diferem entre si pelo teste de Tukey $(\mathrm{P}<0,05)$.

TABELA 4: Médias e desvios padrão dos folículos primordiais, primários e pré-antrais de fetos zebuínos nos vários períodos de gestação. Araçatuba (SP), 2008.

\begin{tabular}{|c|c|c|c|c|}
\hline \multirow{2}{*}{ Variável } & \multirow{2}{*}{$\begin{array}{c}\text { Idade } \\
\text { (meses) }\end{array}$} & \multicolumn{3}{|c|}{ Folículo } \\
\hline & & Primordial & Primário & Pré-antral \\
\hline \multirow{3}{*}{ Diâmetro máximo $(\mu \mathrm{m})$} & 6 & $33,90 \pm 3,11 \mathrm{bB}$ & $42,66 \pm 1,77 \mathrm{aB}$ & $76,52 \pm 17,03 \mathrm{aA}$ \\
\hline & 7 & $44,97 \pm 2,53 \mathrm{aB}$ & $44,71 \pm 2,19 \mathrm{aB}$ & $84,01 \pm 13,97 \mathrm{aA}$ \\
\hline & 8 & $34,04 \pm 3,43 \mathrm{bB}$ & $46,46 \pm 9,05 \mathrm{aB}$ & $65,75 \pm 13,93 \mathrm{aA}$ \\
\hline \multirow{3}{*}{ Diâmetro mínimo $(\mu \mathrm{m})$} & 6 & $27,97 \pm 3,01 \mathrm{bB}$ & $34,13 \pm 2,71 \mathrm{aB}$ & $58,77 \pm 12,68 \mathrm{abA}$ \\
\hline & 7 & $35,86 \pm 2,65 \mathrm{aB}$ & $35,62 \pm 2,28 \mathrm{aB}$ & $68,05 \pm 9,78 \mathrm{aA}$ \\
\hline & 8 & $26,51 \pm 3,56 \mathrm{bB}$ & $34,12 \pm 5,19 \mathrm{aB}$ & $49,23 \pm 7,51 \mathrm{bA}$ \\
\hline \multirow{3}{*}{ Área $\left(\mu \mathrm{m}^{2}\right)$} & 6 & $763,35 \pm 151,66 \mathrm{bB}$ & $1144,06 \pm 168,47 \mathrm{aB}$ & $3912,30 \pm 1789,54 \mathrm{aA}$ \\
\hline & 7 & $1388,90 \pm 168,91 \mathrm{aB}$ & $1364,45 \pm 122,78 \mathrm{aB}$ & $5106,05 \pm 1502,37 \mathrm{aA}$ \\
\hline & 8 & $760,57 \pm 222,03 \mathrm{bB}$ & $1356,39 \pm 461,63 \mathrm{aB}$ & $2900,62 \pm 966,20 \mathrm{aA}$ \\
\hline \multirow{3}{*}{ Perímetro $(\mu \mathrm{m})$} & 6 & $99,91 \pm 8,53 \mathrm{bB}$ & $122,53 \pm 9,37 \mathrm{aB}$ & $223,29 \pm 50,90 \mathrm{aA}$ \\
\hline & 7 & $134,80 \pm 7,08 \mathrm{aB}$ & $133,84 \pm 5,39 \mathrm{aB}$ & $255,43 \pm 39,64 \mathrm{aA}$ \\
\hline & 8 & $100,42 \pm 14,25 \mathrm{bB}$ & $135,75 \pm 23,39 \mathrm{aB}$ & $195,28 \pm 29,93 \mathrm{aA}$ \\
\hline
\end{tabular}

Médias com letras distintas minúsculas, na mesma coluna, e maiúsculas, na mesma linha, diferem entre si pelo teste de Tukey (P<0,05). 

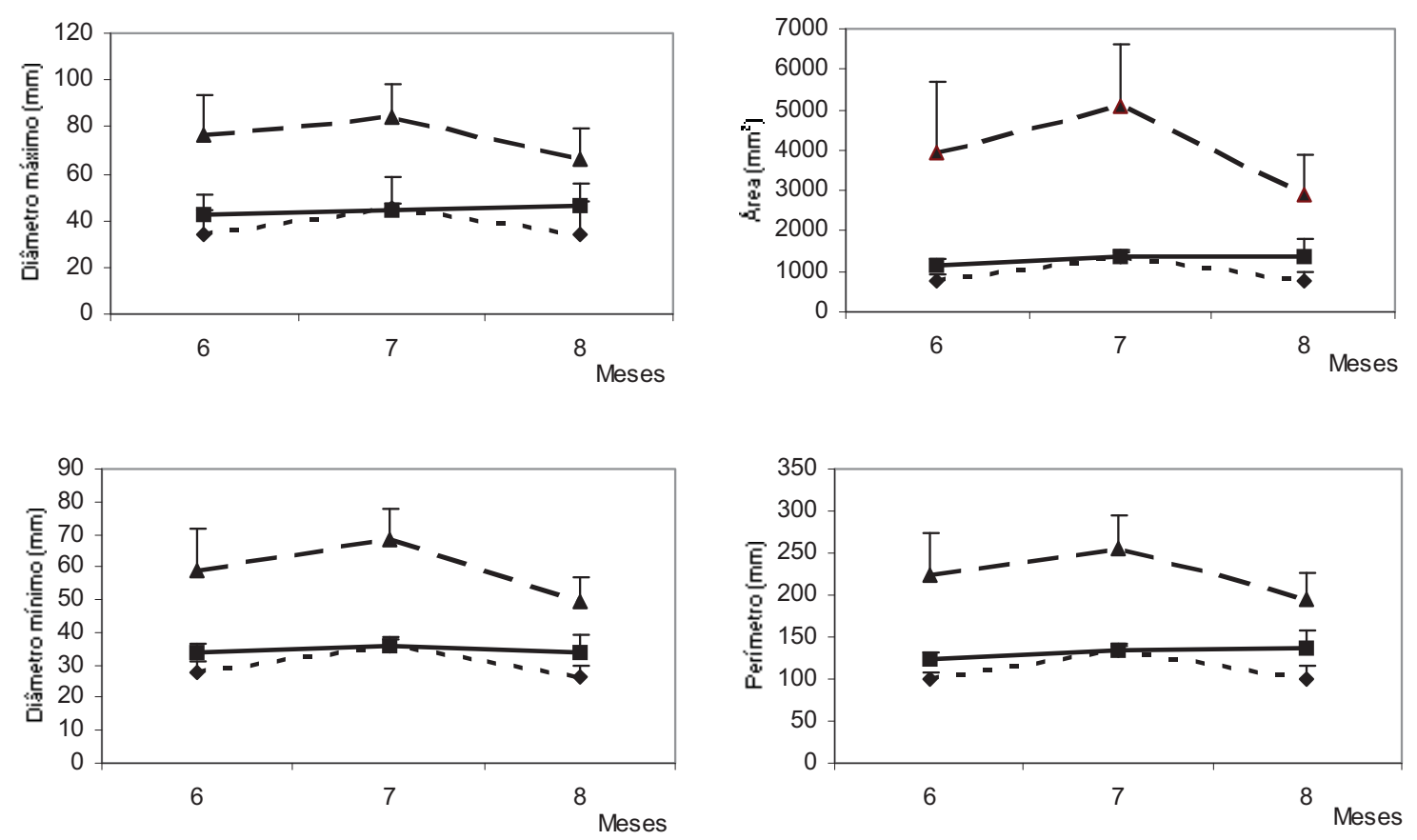

- -๑- - Primordial ——Primário —^Pré-antral

FIGURA 2: Médias dos folículos primordiais, primários e pré-antrais de fetos zebuínos nos vários períodos de gestação. Araçatuba (SP), 2008.

\section{Discussão}

Os fetos em todos os períodos de gestação apresentaram ovários revestidos por epitélio simples cúbico às vezes com epitélio simples pavimentoso e túnica albugínea conforme padrão histológico descrito por Banks (1992), Dellmann (1993) e Hafez e Hafez (2004). Aos três meses, o córtex ovariano estava repleto de folículos primordiais, localizados profundamente próximos a região medular. As médias das medidas foram: diâmetro máximo $33,59 \mu \mathrm{m}$, mínimo $25,94 \mu \mathrm{m}$, área $765,72 \mu \mathrm{m} 2$ e perímetro $99,69 \mu \mathrm{m}$. Diniz et al. (2005) observaram em fetos da raça Nelore com 85 dias gestacionais, início do surgimento de folículos primordiais e aos 94 dias, estavam totalmente formados com diâmetro médio de $35,5 \mu \mathrm{m}$, localizados nas regiões mais profundas do córtex ovariano. No entanto, Mbassa (1989) relatou que em fetos zebuínos, os folículos primordiais são formados a partir de 60 dias pós-coito, diferindo de nossos resultados, pois analisamos fetos a partir de três meses de gestação. No entanto, Moustafa e Hafez (1971) afirmaram que em bovinos europeus os folículos primordiais são formados aos cinco meses de gestação, fato sugestivo da precocidade da foliculogênese das raças zebuínas em relação às européias.

Os folículos primordiais apresentaram as mensurações mais elevadas no período de sete meses de gestação $(44,97 \mu \mathrm{m}$ para diâmetro máximo, $35,86 \mu \mathrm{m}$ para o mínimo, $1388,90 \mu \mathrm{m}^{2}$ para a área e $134,80 \mu \mathrm{m}$ o perímetro) ocorrendo decréscimo para os fetos no $8^{\circ}$ mês de gestação, cujos parâmetros corresponderam àqueles dos fetos nos estágios iniciais de gestação. Diniz et al. (2005) por outro lado, encontraram os maiores diâmetros de folículos primordiais, em fetos aos 180 dias de gestação, porém com diminuição dos mesmos, no período final da gestação o que corrobora nosso resultado. Noden e Lahunta (1990) sugeriram que, provavelmente a redução de diâmetro, pode ser devido ao fato de que, ao final da gestação, esses folículos primordiais restantes serão os dictiótenos que permanecerão no ovário após o nascimento.

Aos quatro meses de gestação, constatou-se aparecimento de folículos primários localizados ora 
mais profundos ora mais superficialmente no córtex ovariano, e no período fetal correspondente a cinco meses, os folículos primordiais e primários estavam localizados logo abaixo da cápsula epitelial que reveste o órgão exteriormente. Os folículos primários mantiveram medidas constantes de crescimento sem diferença significativa, com maior média no período de oito meses, atingindo o diâmetro máximo de $46,46 \mu \mathrm{m}$. Diniz et al. (2005) encontraram aos 140 dias, folículos em crescimento com $46,22 \mu \mathrm{m}$ de diâmetro médio e Mbassa (1989) afirmou que pouco antes dos quatro meses os folículos primários já estavam presentes no córtex ovariano.

A partir dos seis meses de gestação, surgiram folículos pré-antrais, alguns cujos oócitos apresentavam zona pelúcida, localizados aleatoriamente no córtex ovariano e antrais. A partir desse período constatou-se ainda, evidência de atresia folicular. Diniz et al. (2005) afirmaram que aos 180 dias ocorreu o desenvolvimento dos folículos secundários e antrais, muitos deles, já com formação de zona pelúcida ao redor dos oócitos e Monteiro et al. (2003) constataram que ao redor de 22 semanas de gestação, era evidente a presença de folículos em diferentes estágios de crescimento e as variações mais marcantes ocorreram a partir desse período. No entanto, os relatos de Mbassa (1989) e Erickson (1966) diferiram, quando afirmaram respectivamente, que aos 150 dias a foliculogênese atingiu o pico máximo de desenvolvimento e ao redor de 250 dias apareceram os primeiros folículos antrais.

Para os folículos pré-antrais, (assim como os primordiais) as mensurações atingiram o ápice no período gestacional de sete meses $(84,01 \mu \mathrm{m}$ para o diâmetro máximo, $68,05 \mu \mathrm{m}$ para o mínimo, $5106,05 \mu \mathrm{m}^{2}$ para a área e $255,43 \mu \mathrm{m}$ para o perímetro), porém com quedas nos fetos com oito meses de gestação, estas medidas menores ainda que aquelas dos fetos com seis meses. Este acontecimento sugere uma involução do crescimento folicular no período final da gestação, concordando com as afirmações de Diniz et al. (2005). No entanto, tais folículos não desaparecem totalmente, pois de acordo com Mc Natty et al. (1987) muitos folículos pré-antrais e antrais estavam presentes em cordeiros recém nascidos e Hopper et al. (1993) afirmaram que em bezerras recém nascidas, folículos antrais foram observados no córtex ovariano. Por outro lado, Erickson (1966) relatou presença de folículos antrais em bezerras desde o nascimento até 14 dias de idade.

Relativamente à atresia folicular, observou-se também que é comum sua ocorrência nos períodos finais de gestação, confirmado por Mbassa (1989), que observou muitos folículos atrésicos e luteinizados em fetos por volta de 165 a 238 dias de gestação, e por Jantosovicova et al. (1996), que constataram o mesmo em ovelhas na fase imediatamente antes do nascimento.

As médias dos diferentes tipos de folículos ovarianos, comparando-se fetos nos períodos de seis a oito meses de gestação, confirmaram que não houve diferença significante entre as mensurações dos folículos primordiais e primários, porém houve diferença significante entre aqueles folículos e os folículos pré-antrais. Tal ocorrência é esperada devido a maior dimensão dos folículos pré-antrais por apresentarem oócitos grandes, alguns com zona pelúcida e várias camadas de células foliculares ao contrário dos primeiros com apenas uma camada de células foliculares.

Diante dos resultados obtidos pode se concluir que: 1 - nos fetos com três meses de gestação, os ovários apresentaram folículos primordiais, 2 - a partir dos quatro meses de gestação, os ovários já continham folículos primários, 3 - os folículos pré-antrais e antrais surgiram nos ovários de fetos a partir de seis meses de gestação, 4 - as maiores médias foram obtidas aos sete meses de gestação para folículos primordiais e préantrais, tornando a decair aos oito meses.

\section{Referências}

Banks, W. J. 1992. Histologia veterinária aplicada. $2^{a}$ ed. Manole, São Paulo, Brasil, 629pp.

Dellmann, H. D. 1993. Histologia veterinária. 2a ed. Acribia, Zaragoza, España, 398pp.

Diniz, E. G.; Esper, C. R.; Jacomini, J. O.; Vieira, R. C. 2005. Desenvolvimento morfológico dos ovários em embriões e fetos bovinos da raça Nelore. Arquivo Brasileiro de Medicina Veterinária e Zootecnia, 57 (1): 70-76.

Erickson, B. H. 1966. Development and radio-response of the prenatal bovine ovary. Journal of Reproduction and Fertility, 10: 97-105. 
Hafez, E. S. E.; Hafez, B. 2004. Reprodução animal. $7^{\text {a }}$ ed. Manole, São Paulo, Brasil, 513pp.

Hopper, H. W.; Silcose, R. W.; Byerley, D. J.; Kiser, T. E. 1993. Follicular development in prepubertal heifers. Animal Reproduction Science, 31: 7-12.

Jantosovicova, J.; Danko, J.; Jantosovic, J. 1996. A histological study of the follicular development in the prenatal ovary of the sheep. Folia Veterinaria, 64 (12): 9341.

Mbassa, G. K. 1989. Studies on the ovarian development in zebu cattle (Bos indicus). Anatomia, Histologia, Embryologia, 18 (2): 143-149.

McLaren, A. 2000. Germ and somatic cell lineages in fine developing gonad. Molecular and Cellular Endocrinology, 163: 3-9.

Mc Natty, K. P.; Lun, S.; Heath, D. A.; O’Keefe, L. E. 1987. Ovarian follicular activity in Boroola lambs without a fecundity gene. Journal of Reproduction and Fertility, 79: 57-66.

Monteiro, C. M. R.; Carvalhal, R.; Perri, S. H. V. 2003. Análise morfológica dos ovários de fetos bovinos da raça Nelore (Bos primigenius indicus) em diferentes fases de gestação. Brazilian Journal of Veterinary Research Animal Science, 40 (6): 409415.

Motta, P. M.; Makabe, S. 1986. Germ cells in the ovarian surface during fetal development in humans. A three dimensional microanatomical study by scanning and transmission electron microscopy. Journal of Submicroscopy Cytology and Patholology, 81: 271-276.

Moustafa, L. A.; Hafez, E. S. 1971. Prenatal development of the bovine reproductive system. Journal of Reproductive Medicine, 7 (3): 99-113.

Noden, D. M.; Lahunta, A. 1990. Embriologia de los animales domesticos. Acribia, Zaragoza, España, 399pp.

Richardson, C.; Jones, P. C.; Barnard V.; Herbert C. N.; Terlecki, S.; Wijeratne, W. V. S. 1990. Estimation of the developmental age of bovine fetus and newborn calf. The Veterinary Record, 126: 279-284. 